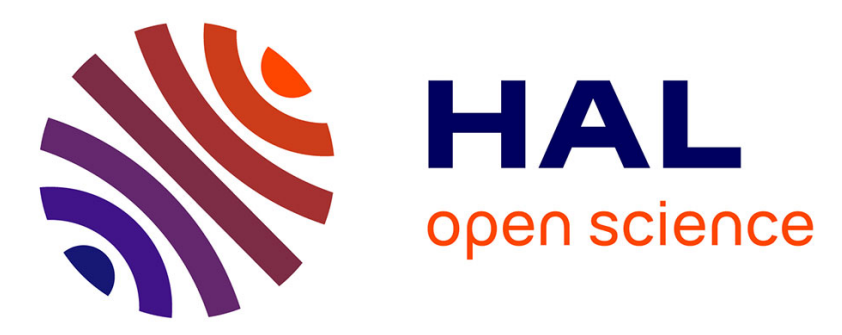

\title{
An MRCI investigation of the electronically excited states of difluorocarbene and its monovalent ions
}

\author{
Jiri Czernek, Oldrich Zivny
}

\section{To cite this version:}

Jiri Czernek, Oldrich Zivny. An MRCI investigation of the electronically excited states of difluorocarbene and its monovalent ions. Molecular Physics, 2008, 106 (14), pp.1761-1765. 10.1080/00268970802275603 . hal-00513219

\section{HAL Id: hal-00513219 \\ https://hal.science/hal-00513219}

Submitted on 1 Sep 2010

HAL is a multi-disciplinary open access archive for the deposit and dissemination of scientific research documents, whether they are published or not. The documents may come from teaching and research institutions in France or abroad, or from public or private research centers.
L'archive ouverte pluridisciplinaire HAL, est destinée au dépôt et à la diffusion de documents scientifiques de niveau recherche, publiés ou non, émanant des établissements d'enseignement et de recherche français ou étrangers, des laboratoires publics ou privés. 


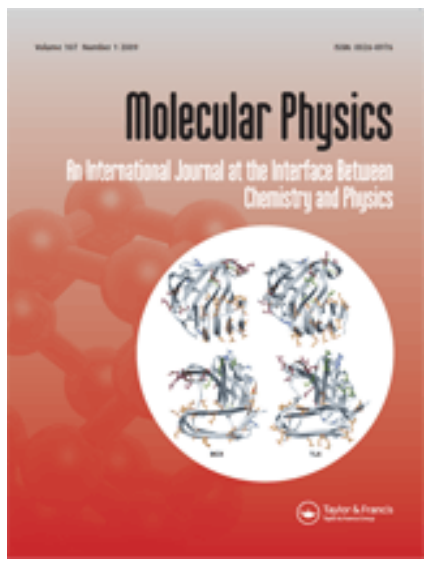

\section{An MRCI investigation of the electronically excited states of difluorocarbene and its monovalent ions}

\begin{tabular}{|c|c|}
\hline Journal: & Molecular Physics \\
\hline Manuscript ID: & TMPH-2008-0141 \\
\hline Manuscript Type: & Full Paper \\
\hline $\begin{array}{r}\text { Date Submitted by the } \\
\text { Author: }\end{array}$ & 08-May-2008 \\
\hline Complete List of Authors: & $\begin{array}{l}\text { Czernek, Jiri; Institute of Macromolecular Chemistry } \\
\text { Zivny, Oldrich; Brno University of Technology, Faculty of Electrical } \\
\text { Engineering and Communication }\end{array}$ \\
\hline Keywords: & carbenes, excited states, ab initio, MRCI, CBS \\
\hline
\end{tabular}

\section{s ScholarONE" \\ Manuscript Central}




\section{An MRCI investigation of the electronically excited states of difluorocarbene and its monovalent ions}

Jiří Czernek* and Oldřich Živnýa ${ }^{a}$

Institute of Macromolecular Chemistry

Academy of Sciences of the Czech Republic

Heyrovsky Square 2

16206 Praha 6

The Czech Republic

Phone: +420-296809290. Fax: +420-296809410. Email: czernek@imc.cas.cz

${ }^{\text {a) }}$ Present address:

Faculty of Electrical Engineering and Communication

Brno University of Technology

Technicka $2848 / 8$

61600 Brno 


\begin{abstract}
The MRCI/CBS computational protocol was employed to describe the low-lying electronic states of $\mathrm{CF}_{2}$ in excellent agreement with experiment. Also of interest for modeling the fluorocarbon plasmas are the difluorocarbene ions, and the geometries, adiabatic excitation energies and orbital characteristics of their electronically excited states were established. Most of the transitions leading to the excited states were found to be monoelectronic and, for the dipole-allowed ones, the oscillator strengths and radiative lifetimes were predicted to aid in the spectroscopic studies.
\end{abstract}




\section{Keywords:}

carbenes; excited states; ab initio; MRCI; CBS 


\section{Introduction}

Multi-reference configuration interaction methods are well-suited for an accurate characterization of molecules in their electronically excited states [1]. We devised the computational protocol, which combines the multiconfigurational-reference internallycontracted configuration interaction (MRCI) [2] technique with extrapolations of the energies to the complete basis set (CBS) limit, and is capable of a highly accurate description of valence electronic states of both neutral and charged species [3]. Most recently we applied this approach to obtain the bond lengths $r_{\mathrm{e}}$, bond angles $\theta$ and adiabatic excitation energies $T_{\mathrm{e}}$ of $\mathrm{NF}_{2}, \mathrm{NF}_{2}^{+}$and $\mathrm{NF}_{2}^{-}$[4] to facilitate the modeling of the $\mathrm{NF}_{3}$ plasma. Due to its vast chemical and technological significance, the $\mathrm{CF}_{2}$ molecule was the subject of numerous experimental and theoretical investigations ( $c f$. Part 3.1), while much less is known about $\mathrm{CF}_{2}^{+}$and $\mathrm{CF}_{2}^{-}$. In particular, the informations describing the geometries and adiabatic electronic transitions in the difluorocarbene ions were obtained only by ab initio calculations or are missing (see Parts 3.2 and 3.3). We employ here the above-mentioned computational strategy to obtain the $r_{\mathrm{e}}, \theta$ and $T_{\mathrm{e}}$ data for a number of electronic states of difluorocarbene and its monovalent ions. We compare our results against the experimental and high-level computational data wherever available, and we describe the $2{ }^{2} \mathrm{~A}_{2}, 2{ }^{2} \mathrm{~B}_{1}$ and $2{ }^{2} \mathrm{~B}_{2}$ states of $\mathrm{CF}_{2}{ }^{+}$and $1{ }^{2} \mathrm{~A}_{2}, 1{ }^{2} \mathrm{~B}_{2}, 2{ }^{2} \mathrm{~A}_{2}, \quad 2^{2} \mathrm{~B}_{1}$ and $2{ }^{2} \mathrm{~B}_{2}$ states of $\mathrm{CF}_{2}^{-}$for the first time. We also predict the oscillator strengths and radiative lifetimes for all the allowed transitions.

\section{Computational methods}

The geometries of the investigated electronic states were obtained using the procedure we described in detail in ref. [3] and only briefly summarize here. The implementation of the MRCI approach [5], [6] was combined with the standard aug-cc-pVQZ basis set [7] (240 basis functions). After a Hartree-Fock calculation, the multiconfigurational self-consistent 


$$
E(X)=E_{\mathrm{CBS}}+b \exp [-(X-1)]+c \exp \left[-(X-1)^{2}\right]
$$

Resulting $E_{C B S}$ data were employed to calculate the adiabatic excitation energies $T_{\mathrm{e}}$ as the differences between the $E_{C B S}$ of the excited and the corresponding ground state. Also for the MRCI/aug-cc-pVQZ geometries, the oscillator strengths $f_{i j}$ of the allowed transitions were obtained from the MRCI vertical excitation energies $T_{\mathrm{v}}^{j}$ and the electronic transition dipole moments in the length form $\boldsymbol{M}_{i j}$ for the transitions between the excited state $j$ and the ground state $i$ as follows: 


$$
f_{i j}=\frac{2}{3} T_{\mathrm{v}}^{j}\left|\boldsymbol{M}_{i j}\right|^{2}
$$

Subsequently, the radiative lifetimes $\tau$ (in seconds) were estimated using Equation (3) (with $T_{\mathrm{v}}^{j}$ and $\boldsymbol{M}_{i j}$ in atomic units).

$$
\tau=\frac{3.1123 \times 10^{-11}}{T_{\mathrm{v}}^{j^{2}} f_{i j}}
$$

In addition, the oscillator strengths and radiative lifetimes were obtained for the MRCI/augcc-pVQZ geometries applying the standard aug-cc-pVDZ basis set [7] together with the equation-of-motion coupled-clusters singles, doubles and triples method (EOM-CCSDT) [13] in the frozen-core approximation (the implementation described in ref. [14]). The MRCI and EOM-CCSDT calculations were performed in Molpro 2006.1 [15] and NWChem 5.0 [16], respectively.

\section{Results and discussion}

\subsection{The difluorocarbene, $\mathrm{CF}_{2}$}

Difluorocarbene is often the principal carbon-bearing component in fluorocarbon plasmas, which are used for a variety of material processing applications [17]. It also plays an important role as the intermediate in chemical reactions, with a markedly different behavior of its singlet and triplet electronic states [18]. As a consequence, the $\mathrm{CF}_{2}$ molecule in the ground and excited states was studied by a number of spectroscopical and theoretical methods (see [19] for a recent review). Significantly, Cai [20] calculated the geometries of the $\mathrm{X}^{1} \mathrm{~A}_{1},{ }^{1} \mathrm{~A}_{2}$, ${ }^{3} \mathrm{~A}_{2},{ }^{1} \mathrm{~B}_{1},{ }^{3} \mathrm{~B}_{1},{ }^{3} \mathrm{~B}_{2}$ states and the corresponding adiabatic excitation energies using the MRCISD/TZ+2P approach, and collected the available experimental and older ab initio results. Table 1 compares our MRCI data with those obtained by Cai and with their experimental counterparts. In spite of an application of rather limited active spaces and of relatively small basis set in [20], the computed values agree fairly well. Thus, the bond 
lengths, bond angles and excitation energies differ at most by ca. $5 \mathrm{pm}, 2^{\circ}$ and one third of $\mathrm{eV}$, respectively ( $c f$. Table 1 ). Importantly, the computational results closely match the measured values, the biggest discrepancy being the $0.14 \mathrm{eV}$ difference between the MRCI/CBS and the experimental adiabatic excitation energy of the ${ }^{3} \mathrm{~B}_{1}$ state (Table 1).

\section{Table 1}

The MRCISD/TZ+2P approach was also applied to predict the oscillator strength and radiative lifetime of the $1{ }^{1} \mathrm{~B}_{1} \rightarrow \mathrm{X}^{1} \mathrm{~A}_{1}$ transition [20]. Interestingly, the results substantially differ from the MRCI and EOM-CCSDT values obtained using the aug-cc-pVDZ basis set (see Table 2). We note in passing that our MRCI calculations are almost unaffected by the choice of the basis set (the aug-cc-pV5Z result for $f$ and $\tau$ are 0.0408 and 20.73 ns accordingly, to be compared to their aug-cc-pVDZ counterparts of 0.0413 and 20.68, respectively), and the EOM-CCSDT computations are too demanding to study the basis set dependence of the results.

\section{Table 2}

The MRCI calculations reveal the details of the electronic transitions leading to the excited states. The configuration of the ground $\left(\mathrm{X}^{1} \mathrm{~A}_{1}\right)$ state of the $\mathrm{CF}_{2}$ in its $\mathrm{MRCI} / \mathrm{aug}-\mathrm{cc}-\mathrm{pVQZ}$ geometry is

$$
\left(1 b_{2}\right)^{2}\left(1 a_{1}\right)^{2}\left(2 a_{1}\right)^{2}\left(3 a_{1}\right)^{2}\left(2 b_{2}\right)^{2}\left(4 a_{1}\right)^{2}\left(3 b_{2}\right)^{2}\left(5 a_{1}\right)^{2}\left(1 b_{1}\right)^{2}\left(1 a_{2}\right)^{2}\left(4 b_{2}\right)^{2}\left(6 a_{1}\right)^{2}\left(2 b_{1}\right)^{0},
$$

with the MRCI/aug-cc-pVQZ reference coefficient of 0.921 . Table 3 characterizes the ${ }^{1} \mathrm{~A}_{2}$, ${ }^{3} \mathrm{~A}_{2},{ }^{1} \mathrm{~B}_{1},{ }^{3} \mathrm{~B}_{1},{ }^{3} \mathrm{~B}_{2}$ excited states of $\mathrm{CF}_{2}$ in terms of their configurations and occupational numbers of the orbitals involved in the corresponding excitations. Clearly, all these states are dominated by one-electron transitions (see Table 3).

\section{Table 3}




\subsection{The difluorocarbene cation, $\mathrm{CF}_{2}{ }^{+}$}

The geometries and excitation energies of $\mathrm{CF}_{2}{ }^{+}$were studied by MRSDCI/DZP calculations in ref. [21], which also summarizes previous work on this molecule. We applied the same technique, which successfully described the $\mathrm{CF}_{2}$ molecule, to investigate the $\mathrm{X}^{2} \mathrm{~A}_{1}, 1^{2} \mathrm{~A}_{2}, 2$ ${ }^{2} \mathrm{~A}_{2}, 1{ }^{2} \mathrm{~B}_{1}, 2{ }^{2} \mathrm{~B}_{1}, 1{ }^{2} \mathrm{~B}_{2}$ and $2{ }^{2} \mathrm{~B}_{2}$ electronic states of $\mathrm{CF}_{2}{ }^{+}$. The configuration of the ground state (the reference coefficient of 0.924 ) is predicted to be

$$
\left(1 b_{2}\right)^{2}\left(1 a_{1}\right)^{2}\left(2 a_{1}\right)^{2}\left(3 a_{1}\right)^{2}\left(2 b_{2}\right)^{2}\left(4 a_{1}\right)^{2}\left(3 b_{2}\right)^{2}\left(1 b_{1}\right)^{2}\left(5 a_{1}\right)^{2}\left(1 a_{2}\right)^{2}\left(4 b_{2}\right)^{2}\left(6 a_{1}\right)^{1}\left(2 b_{1}\right)^{0},
$$

and in Table 3 the configurations of the excited states are presented with respect to it. As was the case of $\mathrm{CF}_{2}$, all the investigated transitions are essentially monoelectronic (cf. Table 3). It can be inferred from Table 4 that our geometries and adiabatic excitation energies are quite similar to those provided by the MRSDCI/DZP calculations [21]. However, the MRSDCI/DZP oscillator strengths and radiative lifetimes differ significantly from both the MRCI and EOM-CCSDT data (see Table 2), probably due to the limited excitation manifold employed in ref. [21].

\section{Table 4}

\subsection{The difluorocarbene anion, $\mathrm{CF}_{2}^{-}$}

We are not aware of any systematical investigation of electronically excited states of $\mathrm{CF}_{2}^{-}$ (the experimental and best theoretical data characterizing the ground state are given in Table 5, and a density functional theory-based description of the first excited state was presented [22]). To fill this gap, we searched for stable structures of the first two electronic states in each of the irreducible representations of the $C_{2 v}$ point group and estimated the resulting MRCI/CBS adiabatic excitation energies. Six excited states were located, which are summarized in Table 5. The oscillator strengths and radiative lifetimes of the dipole-allowed 
transitions were predicted (see Table 2). According to the MCSCF/aug-cc-pVQZ natural orbitals, the configuration of the ground state (the ${ }^{2} \mathrm{~B}_{1}$ symmetry) was found to be

$$
\left(1 b_{2}\right)^{2}\left(1 a_{1}\right)^{2}\left(2 a_{1}\right)^{2}\left(3 a_{1}\right)^{2}\left(2 b_{2}\right)^{2}\left(4 a_{1}\right)^{2}\left(3 b_{2}\right)^{2}\left(5 a_{1}\right)^{2}\left(1 b_{1}\right)^{2}\left(1 a_{2}\right)^{2}\left(4 b_{2}\right)^{2}\left(6 a_{1}\right)^{2}\left(2 b_{1}\right)^{1} .
$$

Its reference coefficient as provided by the MRCI/aug-cc-pVQZ is 0.935 , with the occupational number of the $2 b_{1}$ natural orbital equal to 0.998 . The single-electron replacements leading to the $1{ }^{2} \mathrm{~A}_{1}, 1{ }^{2} \mathrm{~B}_{2}, 1{ }^{2} \mathrm{~A}_{2}, 2{ }^{2} \mathrm{~A}_{2}$ excited states are specified in Table 3 together with the two-electron excitations forming the $2{ }^{2} \mathrm{~B}_{2}$ state. The electronic configuration of the $2^{2} \mathrm{~B}_{1}$ state contains a significant contribution from the ground state ( $c f$. Table 3).

\section{Table 5}

\section{Conclusions}

The MRCI-based computational protocol was employed to describe the low-lying electronic states of $\mathrm{CF}_{2}$ in excellent agreement with experiment. Also of interest for modeling the fluorocarbon plasmas are the difluorocarbene ions and hence the MRCI/aug-cc-pVQZ geometries and orbital characteristics of the $\mathrm{X}^{2} \mathrm{~A}_{1},{ }^{2} \Pi_{\mathrm{u}}, 1{ }^{2} \mathrm{~A}_{2}, 1{ }^{2} \mathrm{~B}_{2}, 2{ }^{2} \mathrm{~A}_{2}, 2{ }^{2} \mathrm{~B}_{1}$ and $2{ }^{2} \mathrm{~B}_{2}$ states of $\mathrm{CF}_{2}^{+}$and the $\mathrm{X}^{2} \mathrm{~B}_{1}, 1{ }^{2} \mathrm{~A}_{1}, 1{ }^{2} \mathrm{~A}_{2}, 1{ }^{2} \mathrm{~B}_{2}, 2{ }^{2} \mathrm{~A}_{2}, 2{ }^{2} \mathrm{~B}_{1}$ and $2{ }^{2} \mathrm{~B}_{2}$ states of $\mathrm{CF}_{2}^{-}$were established. The adiabatic excitation energies of all the species were extrapolated to the CBS limit. The transitions leading to the excited states were found to be monoelectronic (with the exception of the $\mathrm{X}^{2} \mathrm{~B}_{1} \rightarrow 2{ }^{2} \mathrm{~B}_{2}$ of $\mathrm{CF}_{2}^{-}$) and, for the dipole-allowed ones, the oscillator strengths and radiative lifetimes were predicted to aid in the spectroscopic studies. 


\section{Acknowledgements}

This work has been supported by the Czech Science Foundation (Grant 102/06/1337). NWChem Version 5.0, as developed and distributed by Pacific Northwest National Laboratory, P. O. Box 999, Richland, Washington 99352 USA, and funded by the U. S. Department of Energy, was used to obtain some of these results. 


\section{References}

[1] C. D. Sherrill, H. F. Schaefer, Adv. Quantum Chem. 34, 143 (1999).

[2] P. J. Knowles, H.-J. Werner, Theor. Chim. Acta 84, 95 (1992).

[3] J. Czernek, O. Živný, Chem. Phys. 344, 142 (2008).

[4] J. Czernek, O. Živný, Chem. Phys. Lett. (2008), doi: 10.1016/j.cplett.2008.04.039.

[5] H.-J. Werner, P. J. Knowles, J. Chem. Phys. 89, 5803 (1988).

[6] P. J. Knowles, H.-J. Werner, Chem. Phys. Lett. 145, 514 (1988).

[7] R. A. Kendall, T. H. Dunning, Jr., R. J. Harrison, J. Chem. Phys. 96, 6796 (1992).

[8] H.-J. Werner, P. J. Knowles, J. Chem. Phys. 82, 5053 (1985).

[9] P. J. Knowles, H.-J. Werner, Chem. Phys. Lett. 115, 259 (1985).

[10] W. C. Ermler, H. C. Hsieh, L. B. Harding, Comput. Phys. Commun. 51, 527 (1988).

[11] D. E. Woon, T. H. Dunning, Jr., J. Chem. Phys. 103 (1995) 4572.

[12] K. A. Peterson, D. E. Woon, T. H. Dunning, Jr., J. Chem. Phys. 100, 7410 (1994).

[13] S. A. Kucharski et al., J. Chem. Phys. 115, 8263 (2001).

[14] S. Hirata, J. Chem. Phys. 121, 51 (2004).

[15] MOLPRO, version 2006.1, a package of ab initio programs, H.-J. Werner, P. J. Knowles, R. Lindh, F. R. Manby, M. Schütz, and others, see http://www.molpro.net.

[16] R. A. Kendall et al., Comput. Phys. Commun. 128, 260 (2000).

[17] N. Bulcourt et al., J. Chem. Phys. 120, 9499 (2004).

[18] D. L. S. Brahms, W. P. Dailey, Chem. Rev. 96, 1585 (1996).

[19] F. Chau et al., ChemPhysChem 6, 2037 (2006).

[20] Z.-L. Cai, J. Phys. Chem. 97, 8399 (1993).

[21] Z.-L. Cai, Theor. Chim. Acc. 86, 249 (1993).

[22] G. L. Gutsev, T. Ziegler, J. Phys. Chem. 95, 7220 (1991).

[23] W. H. Kirchhoff, D. R. Lide, Jr., F. X. Powell, J. Mol. Spectrosc. 47, 491 (1973). 
[24] S. Koda, Chem. Phys. Lett. 55, 353 (1978).

[25] C. W. Mathews, Can. J. Phys. 45, 2355 (1967).

[26] E. A. Carter, W. A. Goddard, J. Phys. Chem. 91, 4651 (1987).

[27] J. Liang, X. Kong, X. Zhang, H. Li, J. Mol. Struct. (Theochem) 672, 133 (2004).

[28] K. K. Murray et al., J. Chem. Phys. 89, 5442 (1988). 
Table 1. The computational and experimental results for the low-lying electronic states of $\mathrm{CF}_{2}$. See the text for details.

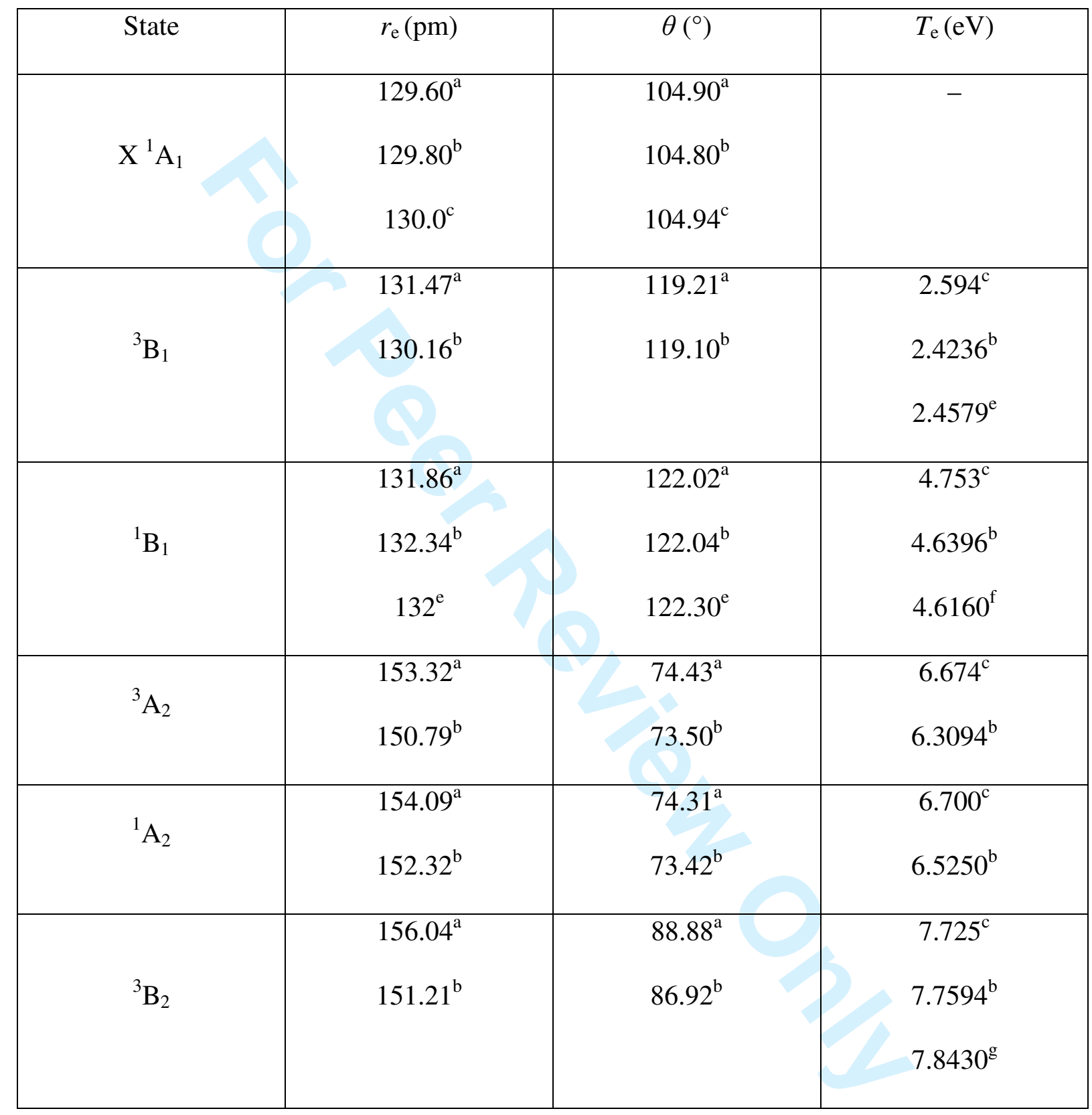

${ }^{\text {a }}$ The MRCI/aug-cc-pVQZ value (this work).

${ }^{\mathrm{b}}$ The MRCISD/TZ+2P value from ref. [20].

${ }^{\mathrm{c}}$ The MRCI/CBS value (this work).

${ }^{\mathrm{d}}$ The experimental value from ref. [23]. 
${ }^{\mathrm{e}}$ The experimental value from ref. [24].

${ }^{\mathrm{f}}$ The experimental value from ref. [25].

${ }^{\mathrm{g}}$ The experimental value from ref. [26]. 
Table 2. The oscillator strengths $f$ and the radiative lifetimes $\tau$ calculated for the MRCI/augcc-pVQZ geometries by various methods. See the text for details.

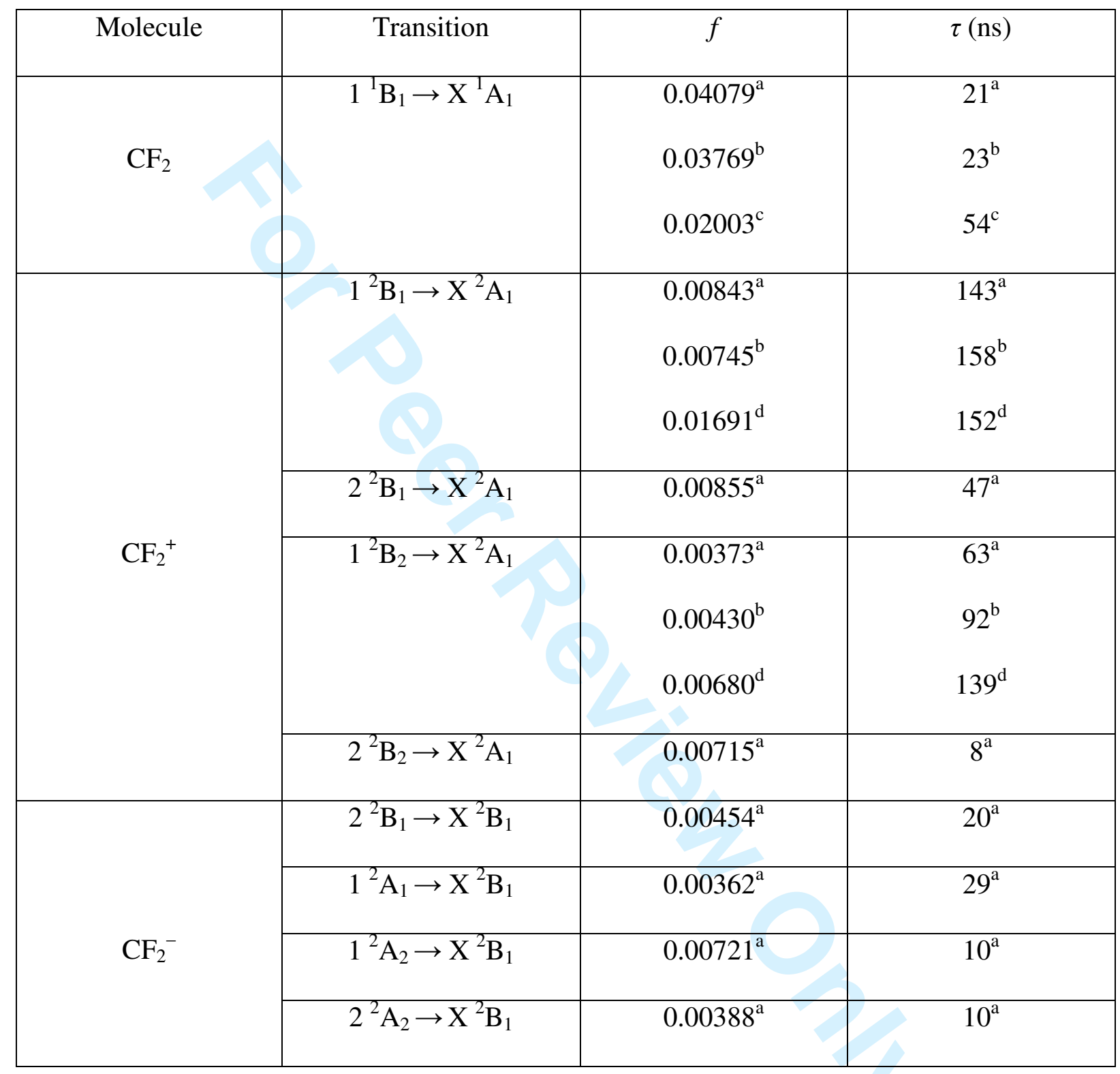

${ }^{\mathrm{a}}$ The MRCI/aug-cc-pVDZ value (this work).

${ }^{\mathrm{b}}$ The EOM-CCSDT/aug-cc-pVDZ value (this work).

${ }^{\mathrm{c}}$ The MRCISD/TZ+2P value from ref. [20].

${ }^{\mathrm{d}}$ The MRCISD/DZP value from ref. [21]. 
Table 3. The leading MRCI/aug-cc-pVQZ reference configurations and the orbital characteristics of the excited states. See the text for details.

\begin{tabular}{|c|c|c|c|}
\hline Molecule & State & Configuration $^{\mathrm{a}}$ & $\begin{array}{c}\text { Coefficients of the } \\
\text { natural orbitals }\end{array}$ \\
\hline \multirow{5}{*}{$\mathrm{CF}_{2}$} & ${ }^{3} \mathrm{~B}_{1}$ & $0.932\left(6 \mathrm{a}_{1} \rightarrow 2 \mathrm{~b}_{1}\right)$ & $\begin{array}{l}1.002\left(6 \mathrm{a}_{1}\right), \\
1.002\left(2 \mathrm{~b}_{1}\right)\end{array}$ \\
\hline & ${ }^{1} \mathrm{~B}_{1}$ & $0.919\left(6 \mathrm{a}_{1} \rightarrow 2 \mathrm{~b}_{1}\right)$ & $\begin{array}{l}1.007\left(6 \mathrm{a}_{1}\right), \\
1.006\left(2 \mathrm{~b}_{1}\right)\end{array}$ \\
\hline & ${ }^{3} \mathrm{~A}_{2}$ & $\begin{array}{r}0.874\left(4 b_{2} \rightarrow 2 b_{1}\right) \\
-0.265\left(3 b_{2} \rightarrow 2 b_{1}\right)\end{array}$ & $\begin{array}{l}1.038\left(4 b_{2}\right) \\
1.001\left(2 b_{1}\right) \\
1.952\left(3 b_{2}\right)\end{array}$ \\
\hline & ${ }^{1} \mathrm{~A}_{2}$ & $0.909\left(4 b_{2} \rightarrow 2 b_{1}\right)$ & $\begin{array}{l}1.038\left(4 b_{2}\right), \\
1.002\left(2 b_{1}\right)\end{array}$ \\
\hline & ${ }^{3} \mathrm{~B}_{2}$ & $0.897\left(1 \mathrm{a}_{2} \rightarrow 2 \mathrm{~b}_{1}\right)$ & $\begin{array}{l}1.074\left(1 \mathrm{a}_{2}\right), \\
0.996\left(2 \mathrm{~b}_{1}\right)\end{array}$ \\
\hline \multirow{4}{*}{$\mathrm{CF}_{2}^{+}$} & $1{ }^{2} \mathrm{~B}_{2}$ & $0.908\left(4 b_{2} \rightarrow 6 a_{1}\right)$ & $1.900\left(6 \mathrm{a}_{1}\right)$ \\
\hline & $1{ }^{2} \mathrm{~A}_{2}$ & $0.894\left(1 \mathrm{a}_{2} \rightarrow 6 \mathrm{a}_{1}\right)$ & $\begin{array}{l}1.900\left(6 \mathrm{a}_{1}\right), \\
1.039\left(1 \mathrm{a}_{2}\right)\end{array}$ \\
\hline & $2^{2} \mathrm{~B}_{1}$ & $\begin{array}{c}0.814\left(1 b_{1} \rightarrow 6 a_{1}\right)- \\
0.244\left(6 a_{1} \rightarrow 2 b_{1}\right)\end{array}$ & $\begin{array}{l}1.208\left(1 b_{1}\right) \\
1.694\left(6 a_{1}\right) \\
0.226\left(2 b_{1}\right)\end{array}$ \\
\hline & $2{ }^{2} \mathrm{~A}_{2}$ & $0.908\left(4 b_{2} \rightarrow 2 b_{1}\right)$ & $1.038\left(4 b_{2}\right)$ \\
\hline
\end{tabular}




\begin{tabular}{|c|c|c|c|}
\hline & & & $1.005\left(2 b_{1}\right)$ \\
\hline & $2{ }^{2} \mathrm{~B}_{2}$ & $\begin{array}{r}0.651\left(3 \mathrm{~b}_{2} \rightarrow 6 \mathrm{a}_{1}\right) \\
-0.613\left(1 \mathrm{a}_{2} \rightarrow 2 \mathrm{~b}_{1}\right)\end{array}$ & $\begin{array}{l}1.967\left(3 \mathrm{~b}_{2}\right), \\
1.479\left(6 \mathrm{a}_{1}\right), \\
1.546\left(1 \mathrm{a}_{2}\right), \\
0.523\left(2 \mathrm{~b}_{1}\right)\end{array}$ \\
\hline \multirow{6}{*}{$\mathrm{CF}_{2}^{-}$} & $1^{2} \mathrm{~A}_{1}$ & $0.940\left(2 b_{1} \rightarrow 7 a_{1}\right)$ & $\begin{array}{l}0.061\left(2 b_{1}\right), \\
0.997\left(7 a_{1}\right)\end{array}$ \\
\hline & $1^{2} \mathrm{~B}_{2}$ & $0.940\left(2 b_{1} \rightarrow 5 b_{2}\right)$ & $\begin{array}{l}0.075\left(2 b_{1}\right), \\
0.998\left(5 b_{2}\right)\end{array}$ \\
\hline & $2{ }^{2} B_{1}$ & $\begin{array}{c}0.565\left(6 a_{1} \rightarrow 7 a_{1}\right) \\
-0.555\left(6 a_{1} \rightarrow 7 a_{1}\right) \\
-0.510 \text { (the ground } \\
\text { state) }\end{array}$ & $\begin{array}{l}1.533\left(6 a_{1}\right), \\
0.453\left(7 a_{1}\right), \\
0.996\left(2 b_{1}\right)\end{array}$ \\
\hline & $1^{2} \mathrm{~A}_{2}$ & $0.947\left(6 \mathrm{a}_{1} \rightarrow 5 \mathrm{~b}_{2}\right)$ & $\begin{array}{l}0.999\left(6 \mathrm{a}_{1}\right), \\
0.998\left(5 \mathrm{~b}_{2}\right)\end{array}$ \\
\hline & $2^{2} \mathrm{~A}_{2}$ & $0.941\left(6 \mathrm{a}_{1} \rightarrow 5 \mathrm{~b}_{2}\right)$ & $\begin{array}{l}1.002\left(6 \mathrm{a}_{1}\right), \\
0.997\left(5 \mathrm{~b}_{2}\right)\end{array}$ \\
\hline & $2{ }^{2} \mathrm{~B}_{2}$ & $\begin{array}{c}0.744 \\
\left(6 \mathrm{a}_{1} 2 \mathrm{~b}_{1} \rightarrow 7 \mathrm{a}_{1} 5 \mathrm{~b}_{2}\right) \\
+0.558 \\
\left(6 \mathrm{a}_{1} 2 \mathrm{~b}_{1} \rightarrow 7 \mathrm{a}_{1} 5 \mathrm{~b}_{2}\right)\end{array}$ & $\begin{array}{l}1.164\left(6 a_{1}\right), \\
0.048\left(2 b_{1}\right), \\
0.828\left(7 a_{1}\right), \\
0.998\left(5 b_{2}\right)\end{array}$ \\
\hline
\end{tabular}

${ }^{\text {a }}$ Excitations given relative to the reference configurations described for the respective molecules in Part 3. 
Table 4. The computational results for the low-lying electronic states of $\mathrm{CF}_{2}{ }^{+}$. See the text for details.

\begin{tabular}{|c|c|c|c|}
\hline State & $r_{\mathrm{e}}(\mathrm{pm})$ & $\theta\left(^{\circ}\right)$ & $T_{\mathrm{e}}(\mathrm{eV})$ \\
\hline $\mathrm{X}^{2} \mathrm{~A}_{1}$ & $121.47^{\mathrm{a}}$ & $124.82^{\mathrm{a}}$ & \\
& $122.2^{\mathrm{b}}$ & $124.5^{\mathrm{b}}$ & $2.985^{\mathrm{c}}$ \\
\hline $1^{2} \mathrm{~B}_{1}\left({ }^{2} \Pi_{\mathrm{u}}\right)$ & $122.86^{\mathrm{a}}$ & 180.0 & $2.799^{\mathrm{b}}$ \\
& $123.2^{\mathrm{b}}$ & & $4.552^{\mathrm{c}}$ \\
\hline $1{ }^{2} \mathrm{~B}_{2}$ & $137.22^{\mathrm{a}}$ & $84.14^{\mathrm{a}}$ & $4.658^{\mathrm{b}}$ \\
\hline $1^{2} \mathrm{~A}_{2}$ & $137.0^{\mathrm{b}}$ & $86.0^{\mathrm{b}}$ & $5.554^{\mathrm{c}}$ \\
& $139.56^{\mathrm{a}}$ & $95.69^{\mathrm{a}}$ & $5.673^{\mathrm{b}}$ \\
\hline $2^{2} \mathrm{~B}_{1}$ & $140.1^{\mathrm{b}}$ & $97.6^{\mathrm{b}}$ & $7.272^{\mathrm{c}}$ \\
\hline $2^{2} \mathrm{~A}_{2}$ & $145.42^{\mathrm{a}}$ & $104.56^{\mathrm{a}}$ & $7.404^{\mathrm{c}}$ \\
\hline $2^{2} \mathrm{~B}_{2}$ & $136.48^{\mathrm{a}}$ & $93.01^{\mathrm{a}}$ & $8.033^{\mathrm{c}}$ \\
\hline
\end{tabular}

${ }^{\text {a }}$ The MRCI/aug-cc-pVQZ value (this work).

${ }^{\mathrm{b}}$ The MRCISD/DZP value from ref. [21].

${ }^{\mathrm{c}}$ The MRCI/CBS value (this work). 
Table 5. The computational and experimental results for the low-lying electronic states of $\mathrm{CF}_{2}^{-}$. See the text for details.

\begin{tabular}{|c|c|c|c|}
\hline State & $r_{\mathrm{e}}(\mathrm{pm})$ & $\theta\left(^{\circ}\right)$ & $T_{\mathrm{e}}(\mathrm{eV})$ \\
\hline & $143.77^{\mathrm{a}}$ & $98.99^{\mathrm{a}}$ & \\
\hline $\mathrm{X}^{2} \mathrm{~B}_{1}$ & $145.09^{\mathrm{b}}$ & $100.079^{\mathrm{b}}$ & \\
& $145 \pm 2^{\mathrm{c}}$ & $99 \pm 2^{\mathrm{c}}$ & $0.819^{\mathrm{d}}$ \\
\hline $1^{2} \mathrm{~A}_{1}$ & $128.22^{\mathrm{a}}$ & $106.00^{\mathrm{a}}$ & $3.393^{\mathrm{d}}$ \\
\hline $1^{2} \mathrm{~B}_{2}$ & $163.19^{\mathrm{a}}$ & $82.17^{\mathrm{a}}$ & $3.471^{\mathrm{d}}$ \\
\hline $1^{2} \mathrm{~A}_{2}$ & $130.06^{\mathrm{a}}$ & $118.52^{\mathrm{a}}$ & $3.710^{\mathrm{d}}$ \\
\hline $2^{2} \mathrm{~B}_{1}$ & $130.90^{\mathrm{a}}$ & $116.59^{\mathrm{a}}$ & $5.859^{\mathrm{d}}$ \\
\hline $2^{2} \mathrm{~A}_{2}$ & $129.83^{\mathrm{a}}$ & $121.78^{\mathrm{a}}$ & $8.131^{\mathrm{d}}$ \\
\hline $2^{2} \mathrm{~B}_{2}$ & $120.90^{\mathrm{a}}$ & $126.05^{\mathrm{a}}$ & \\
\hline
\end{tabular}

${ }^{\text {a }}$ The MRCI/aug-cc-pVQZ value (this work).

${ }^{\mathrm{b}}$ The $\operatorname{CCSD}(\mathrm{T}) / 6-311+\mathrm{G}(2 \mathrm{~d})$ value from ref. [27].

${ }^{\mathrm{c}}$ The experimental value from ref. [28].

${ }^{\mathrm{d}}$ The MRCI/CBS value (this work). 